\title{
Performance Analysis of ODSB-SC Ro-FSO System under Atmospheric Attenuation
}

\author{
Abhishek Konch \\ M.Tech scholar \\ Dept. of ECE \\ SHIATS, Allahabad
}

\author{
Neelesh Agrawal \\ Asst. Professor \\ Dept. of ECE \\ SHIATS, Allahabad
}

\author{
A.K.Jaiswal \\ Professor and H.O.D \\ Dept. of ECE \\ SHIATS, Allahabad
}

\author{
Navendu Nitin \\ Asst. Professor \\ Dept. of ECE \\ SHIATS, Allahabad
}

\begin{abstract}
Radio over free space optics (Ro-FSO) technology provides a promising solution for future wireless network, offering high data transmission compared to RF technology. In this paper, performance of double sideband-suppressed carrier based RoFSO system under various weather conditions is investigated. It transmits two RF signals at 10 and $15 \mathrm{GHz}$ over an optical wireless channel of $1 \mathrm{~km}$. At transmitter Mach Zehnder modulator is used for both carrier suppression and signal modulation. At the receiver, delay interferometer is used for separation of RF signal having delay of $0.1 \mathrm{~ns}$.
\end{abstract}

\section{Keywords}

Radio over free space optics (Ro-FSO), RoF, FSO, ODSB$\mathrm{SC}$, Wavelength interleaving (WI)

\section{INTRODUCTION}

The increased bandwidth demand for future wireless network has led to the rise of optical wireless communication. Ro-FSO technology is the combination of radio over fiber ( $\mathrm{RoF})$ and free space optics (FSO) [1]. The main advantage of RoF is the ability to distribute the RF signal at large bandwidth using optical fiber at lower attenuation, immunity to RF interference and low power consumption. The FSO has similar working principles as optical fiber communication [2] [3]. The only difference is that it utilizes atmosphere for transmission of the signal instead of optical fiber as a channel which help to reduce the cabling cost. FSO also provides highly secure license free operation and high data rate transmission, which makes it to be used in a wide range of wireless service and cellular architecture. The major challenge of free space optics is the atmospheric attenuation. In geographical areas like buildings, hilly terrains, underground, FSO cannot be used due to multipath fading. At such situation FSO technology can be integrated with radio technology to get an uninterruptable wireless service.

In this paper wavelength interleaving (WI) technique has been used for channel spacing of RF signals. WI technique helps to improve the spectral efficiency [4]. The system employing WI technique reduces the channel spacing to the value less than twice the highest modulation frequency. The system having channel spacing smaller than the RF carrier frequency provides better spectral efficiency. At the receiver side interferometer has been used for separating the WI signals. It is found that interferometer with time delay $0.1 \mathrm{~ns}$ provides better performance [5].In this paper, externally modulated two RF signals transmitted at 10 and $15 \mathrm{GHz}$ frequency. In section 2 , simulations setup of RoF-FSO system is discussed .In section 3, the result has been reported .Finally, in section 4, conclusions are made.

\section{SYSTEM DESCRIPTION}

The schematic diagram of proposed Ro-FSO transmission system is shown in fig. 1 . The system consists of two RF signals of $10 \mathrm{GHz}$ and $15 \mathrm{GHz}$. These signals are combined using electrical multiplier and combiner. The RF signals are then passed through Mach-Zehnder modulator which is used for both optical carrier suppression and signal modulation. The continuous wave laser is used at $193.1 \mathrm{THz}$ and power of $20 \mathrm{dBm}$. The optical signal then transmitted over $1 \mathrm{~km}$. through optical wireless channel at reference wavelength of $1550 \mathrm{~nm}$. At the receiver end signal is then passed through an interferometer which separate the RF signal with time delay of $0.1 \mathrm{~ns}$. Each receiver section has a Bessel filter of 193.1 $\mathrm{THz}$ with $40 \mathrm{GHz}$ bandwidth. Optical amplifier has been used having gain of $15 \mathrm{~dB}$. PIN diode is used as a photo detector. The signal is demodulated using AM demodulator with cutoff frequency $1 \mathrm{GHz}$ having bandwidth of $20 \mathrm{GHz}$ and $30 \mathrm{GHz}$ for 10 and $15 \mathrm{GHz}$ wavelength interleaved signals.

The Link Equation of the free space optics is given by [6][7]

$$
P_{\text {Received }}=P_{\text {Transmitted }} \frac{d_{R}^{2}}{\left(d_{T}+\theta R\right)^{2}} 10^{-\alpha R / 10}
$$

Where $d_{R}$ defines receiver antenna aperture diameter and $d_{T}$ is the transmitter antenna aperture diameter. The $\theta$ defines the beam divergence. $\mathrm{R}$ is the range and $\alpha$ is the atmospheric attenuation.

\section{ATMOSPHERIC ATTENUATION}

\subsection{ATTENUATION DUE TO FOG}

The attenuation due to foggy weather is given by Kim's model [8], which is found very accurate for the wavelength range of 750-1550 $\mathrm{nm}$.

$$
\alpha_{F o g}=\frac{3.91}{V}\left(\frac{\lambda}{550}\right)^{-q}
$$

Where $V$ is the visibility, $\lambda$ is the operating wavelength and $q$ is the parameter related to the size of the droplet.

$$
q=\left\{\begin{array}{lr}
1.6 & \text { if } V>50 \mathrm{~km} \\
1.3 & \text { if } 6 \mathrm{~km}<V<50 \mathrm{~km} ; \\
0.16 V+1.34 & \text { if } 1 \mathrm{~km}<V<6 \mathrm{~km} ; \\
V-0.5 & \text { if } 0.5 \mathrm{~km}<V<1 \mathrm{~km} ; \\
0 & \text { if } V<0.5 \mathrm{~km} .
\end{array}\right.
$$




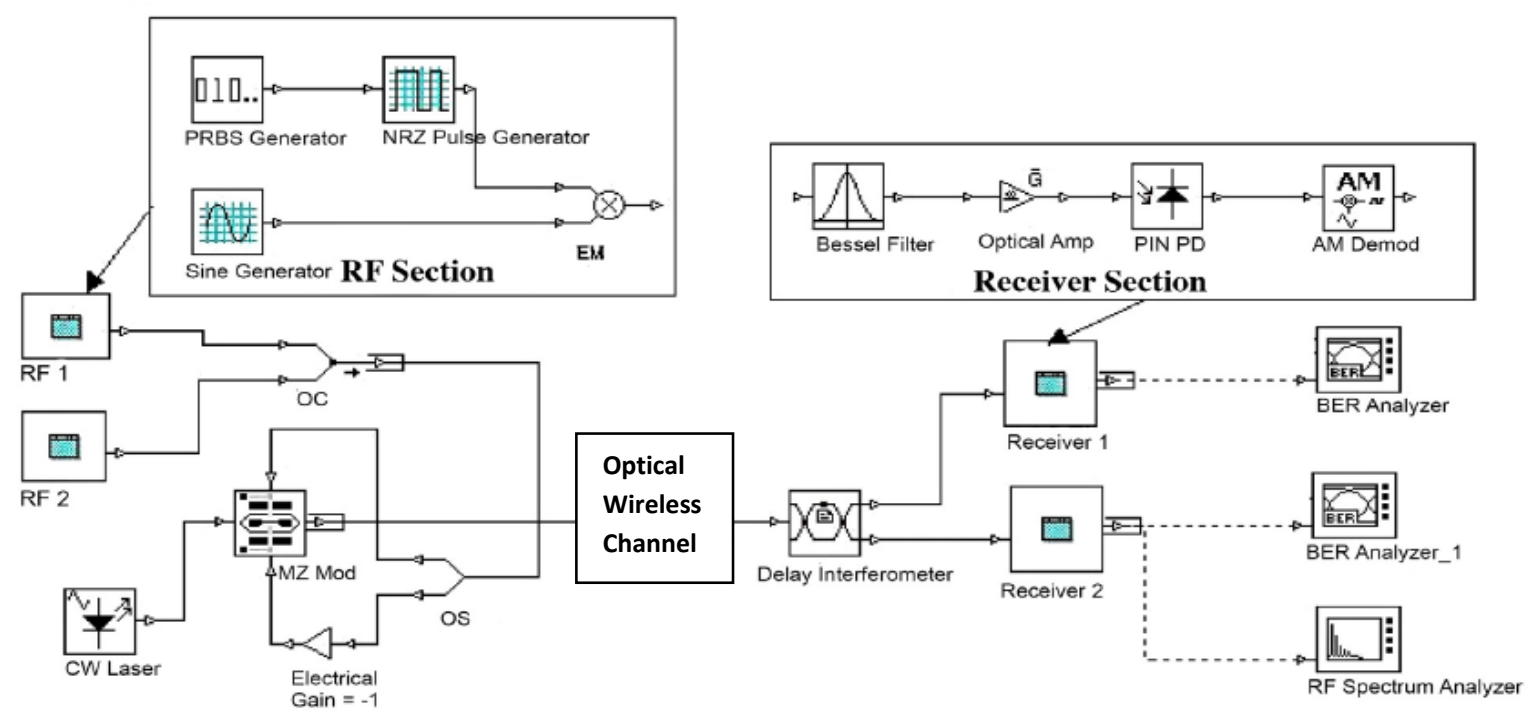

Fig.1. Schematic diagram of ODSB-SC Ro-FSO system

\subsection{ATTENUATION DUE TO RAIN}

In case of rain, the loss in optical power does not depend upon the wavelength. For rain empirical model is based upon the visibility range [9].

$$
\alpha_{\text {Rain }}=\frac{2.9}{V}
$$

\section{RESULT AND DISCUSSION}

For different visibility condition of Fog and Rain the performance of ODSB-SC RoF system is analyzed. Table 1 shows max $\mathrm{Q}$ factor at different Fog visibility condition and Figure 2.1, 2.2 , $2.3 \& 2.4$ shows the Eye Diagram for the 10 $\mathrm{GHz}$ receiver under different visibility condition of $500 \mathrm{~m}$, $400 \mathrm{~m}, 300 \mathrm{~m} \& 200 \mathrm{~m}$.

Table 1. Max. $Q$ factor at different Fog visibility

\begin{tabular}{|c|c|}
\hline $\begin{array}{c}\text { Visibility } \\
\text { (meter) }\end{array}$ & Max Q factor \\
\hline 500 & 17.38 \\
\hline 400 & 11.19 \\
\hline 300 & 4.32 \\
\hline 200 & 0 \\
\hline
\end{tabular}

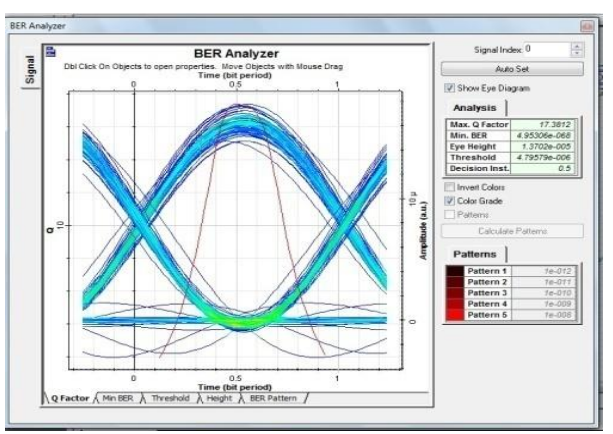

Fig.2.1 EYE Diagram at 500m Fog Visibility

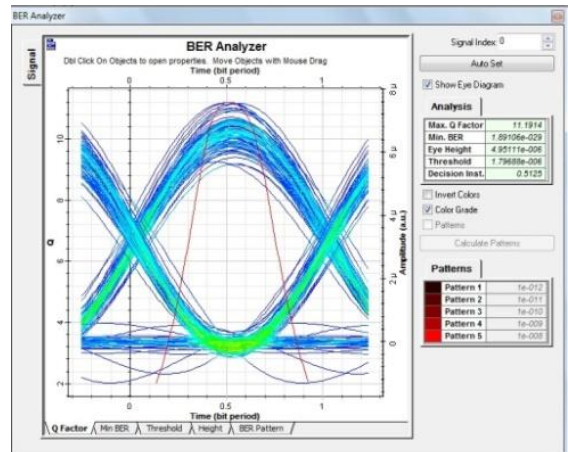

Fig.2.2 EYE Diagram at 400m Fog Visibility

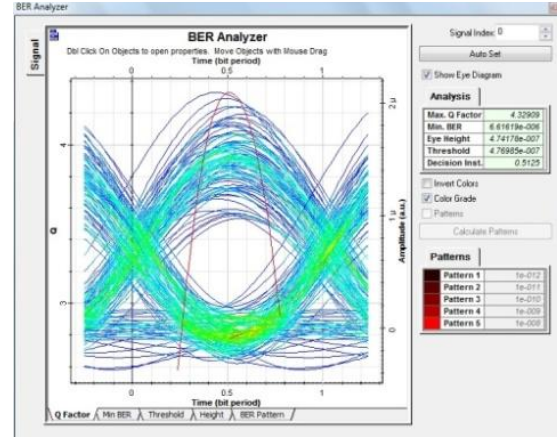

Fig.2.3 EYE Diagram at 300m Fog Visibility

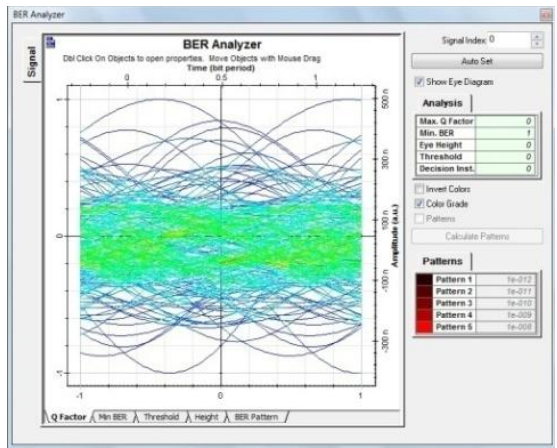

Fig.2.4 EYE Diagram at 200m Fog Visibility 


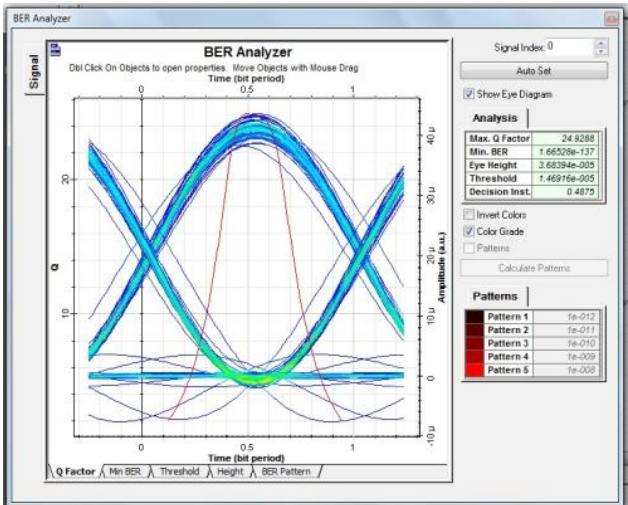

Fig.3.1 EYE Diagram at 500m Rain Visibility

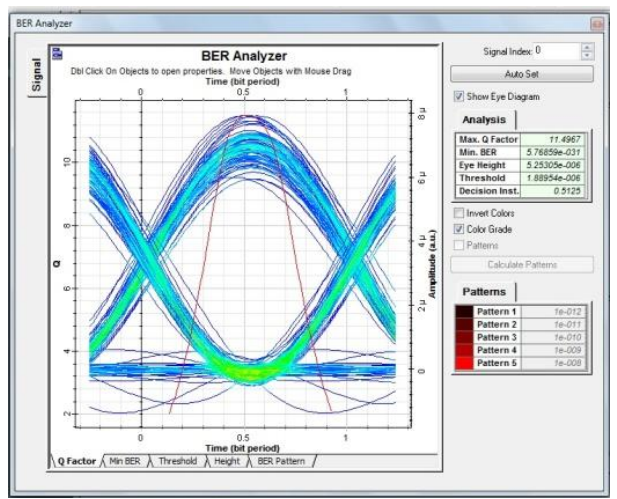

Fig.3.3 EYE Diagram at 300m Rain Visibility

In case of Rain attenuation also optical signal is analyzed at its different visibility. Table 2 shows max Q factor at different Rain visibility condition and Figure 2.1, 2.2 , $2.3 \& 2.4$ shows the Eye Diagram for the $10 \mathrm{GHz}$ receiver under different visibility condition of $500 \mathrm{~m}, 400 \mathrm{~m}, 300 \mathrm{~m} \& 200 \mathrm{~m}$.

Table 2. Max. Q factor at different Rain visibility

\begin{tabular}{|c|c|}
\hline $\begin{array}{c}\text { Visibility } \\
\text { (meter) }\end{array}$ & Max Q factor \\
\hline 500 & 24.92 \\
\hline 400 & 19.42 \\
\hline 300 & 11.49 \\
\hline 200 & 2.64 \\
\hline
\end{tabular}

\section{CONCLUSION}

In this paper simulation of $1 \mathrm{Gbps}$ data transmission is shown. It is found that due to Rain and Fog attenuation, signal in optical wireless channel highly attenuated. Attenuation of optical beam due to the rain is found low compared to the fog. It is also found that as the distance between transmitter and receiver increases the atmospheric effect over the link also increases.

The future work is to reduce the effect of atmospheric attenuation and to increase its range to get a high data rate RoFSO network.

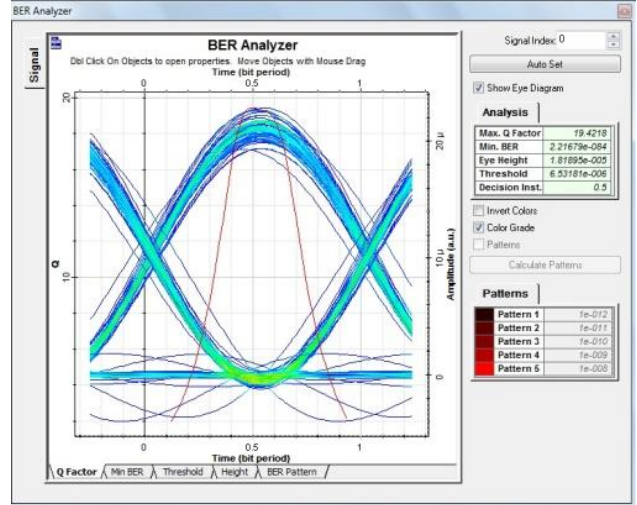

Fig.3.2 EYE Diagram at 400m Rain Visibility

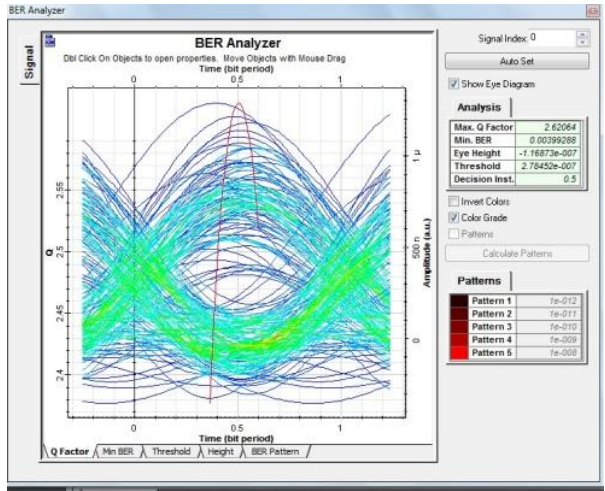

Fig.3.4 EYE Diagram at 200m Rain Visibility

\section{ACKNOWLEDGEMENT}

I would like to thank my adviser Asst. Prof. Neelesh agrawal for his support and encouragement. I would also like to thank Prof. \& Head A.K. Jaiswal and Asst. Prof. Navendu Nitin to provide valuable advices. The product of this research paper would not be possible without all of them.

\section{REFERNCES}

[1] Kamugisha Kazaura, Kazuhiko Wakamori, and Mitsuji Matsumoto, - RoFSO: A Universal Platform for Convergence of Fiber and Free-Space Optical Communication Networks, \| IEEE communication magazine, pp. 130-137, February 2010.

[2] K. Tsukamoto, T. Higashino, T. Nakamura, R. Takahashi and Mitsuji Matsumoto, - Development of Radio on Free Space Optics System for Ubiquitous Wireless, I PIERS Proceedings, Hangzhou, China, March 24-28, 2008.

[3] S.Bloom, E.Korevaar, John Schuster and H.Willebrand, -Understanding the performance of free space optics [invited],\| Journal of optical network, vol. 2, pp. 178200, 2003.

[4] C.Lim, A.Nirmalathas, D.Novak, R.S.Tucker and R.B.Waterhouse, -Wavelength interleaving technique to improve optical spectrum efficiency in millimeter wave WDM fiber radio ,॥ IEEE laser and electro optic society, vol. 1, pp. 54-45, 2001.

[5] Harjit Singh, A.Sheetal and Ajay Kumar, -Impact of interferometer delay time on the performance of ODSBSC RoF system with wavelength interleaving, \| Optik International Journal for light \& electron optics, vol. 125, pp. 2057-2061,May 2014. 
[6] M.S.Awan, Marzuki, E.Leitgeb, F.Nadeem, M.S.Khan and C.Capsoni-Weather effects impact on the optical pulse propagation in free space, $\|$ IEEE $69^{\text {th }}$, Vehicular technology conference, Barcelona, April 2009.

[7] A.Amphawan, S.Chaudhary and V.W.S.Chan, - $2 \times 2$ Gbps 40Ghz OFDM Ro-FSO transmission with mode divison multiplexing, \| Journal of the European optical society, vol. 9, 2014.
[8] I. I. Kim, B. McArthur, and E. Korevaar, - Comparison of laser beam propagation at $785 \mathrm{~nm}$ and $1550 \mathrm{~nm}$ in fog and haze for optical wireless communications, \| Proc. SPIE, 4214, Boston, MA, USA, 2001

[9] D.Atlas, - Shorter contribution optical extinction by rainfall, J.Metrol, vol. 101, pp. 486-488, 1970. 